\title{
Enhancement of Neutrophil Function
}

\section{as a Result of Prior Exposure to Chemotactic Factor}

\author{
Dennis E. VAN Epps and MARy Lynn Garcia, Departments of Medicine and \\ Microbiology, University of New Mexico, School of Medicine, Albuquerque, New \\ Mexico 87131
}

A B S T RAC T Exposure of human polymorphonuclear leukocytes (PMN) to chemotactic factor, as well as the migration of $\mathrm{PMN}$ through a 5- $\mu \mathrm{m}$ pore-size membrane, results in a PMN population with enhanced chemiluminescence, enhanced capacity for superoxide anion production, and increased Escherichia coli bactericidal activity. The enhanced PMN response resulting from exposure to chemotactic factor was observed with several chemotactic stimuli, including a mixture of casein and autologous serum, chemotactic C5 fragment, and formyl-L-methionyl-L-leucine-Lphenylalanine (f-Met-Leu-Phe). Enhanced levels of chemiluminescence were observed with both soluble stimuli (concanavalin $\mathrm{A}$ and phorbol myristate acetate) as well as particulate stimuli (opsonized zymosan).

Once activated by chemotactic factor, PMN retained their enhanced stimulated chemiluminescence in the absence of chemotactic factor for at least $2.5 \mathrm{~h}$. Enhanced activity could not be correlated with a shift in the number of immunoglobulin (Ig)G Fc receptor positive or complement receptor positive PMN. In vivo studies with guinea pigs indicated that PMN attracted to an intraperitoneal injection of casein, like those attracted through a chemotaxis membrane in vitro in response to casein, showed markedly enhanced stimulated chemiluminescence when compared with peripheral blood PMN from the same animal. Such a mechanism to stimulate PMN function may enhance the effectiveness of PMN in host defense at inflammatory foci.

\section{INTRODUCTION}

Chemotaxis is believed to be an important mechanism by which polymorphonuclear leukocytes $(\mathrm{PMN})^{1}$ as

D. E. Van Epps was the recipient of an Arthritis Foundation Senior Investigatorship Award.

Received for publication 5 July 1979 and in revised form 26 March 1980.

${ }^{1}$ Abbreviations used in this paper: Con A, concanavalin A; FCS, fetal calf serum; HBSS, Hanks' balanced salt solution; PMA, phorbol myristate acetate; PMN, polymorphonuclear leukocytes. well as other cells are recruited to inflammatory sites. The attraction of these cells has been attributed to the activation of a variety of chemotactic factors in vivo, including: kallikrein; chemotactic C5 fragment from the complement system; chemotactic factors derived from cells involved in host defense such as lymphocytes, monocytes, and neutrophils; and factors liberated from infecting microorganisms (1). It has also been shown that chemotactic factors can stimulate neutrophil chemiluminescence (2), cause cell aggregation (3), increase intracellular levels of cyclic guanosine $5 '$-monophosphate (cGMP) (4); increase microtubule and microfilament assembly $(5,6)$, stimulate degranulation (7), increase adherence $(6,8)$, and stimulate superoxide anion production $(6,9)$. A recent study by Gallin et al. (10) has shown that under appropriate conditions, factors such as phorbol myristate acetate, concanavalin A (Con A), and the calcium ionophore A23187, which stimulate neutrophil secretion of enzymes, increase adherence and alter the binding of the chemotactic peptide, f-Met-Leu-Phe (10). All of these cited studies indicate that the neutrophils exposed to chemotactic stimuli or agents capable of stimulating degranulation undergo metabolic, cytoskeletal, and surface receptor alterations. The present study demonstrates that neutrophils that either have been exposed to a chemotactic stimulus or have migrated in response to this stimulus are functionally more active in systems measuring stimulated chemiluminescence, superoxide anion generation, and bactericidal activity than those that have not been exposed to chemotactic factor.

\section{METHODS}

Cell preparation. Human PMN were prepared from heparinized peripheral blood by Ficoll-Hypaque centrifugation (11). The cell pellet containing PMN and erythrocytes was resuspended in Hanks' balanced salt solution (HBSS) and mixed with Plasmagel (HTI, Buffalo, N. Y.) at a concentration of $1 \mathrm{ml}$ of Plasmagel per $5 \mathrm{~cm}^{3}$ of blood. The leukocyte-rich supernate obtained after $30 \mathrm{~min}$ of $37^{\circ} \mathrm{C}$ incubation was then centrifuged and the cell pellet mixed with $4^{\circ} \mathrm{C}$ distilled water for $30 \mathrm{~s}$ to lyse residual erythrocytes. Cells were then washed twice and resuspended in 
HBSS supplemented with $5 \%$ fetal calf serum (FCS) to a concentration of $2 \times 10^{7} \mathrm{PMN} / \mathrm{ml}$. This preparation contained $>90 \%$ neutrophils. The cell suspension was then divided into three parts and each was treated in one of the following ways: $(a)$ one part was incubated at $37^{\circ} \mathrm{C}$ for $3 \mathrm{~h}$ in $\mathrm{HBSS}$ supplemented with $5 \%$ FCS; $(b)$ one part was incubated at $37^{\circ} \mathrm{C}$ for $3 \mathrm{~h}$ in $5 \% \mathrm{FCS}$ plus chemotactic factor; $(c)$ the remaining cells in media supplemented with $5 \%$ FCS were placed in the upper compartment of an enlarged Boyden type chemotactic chamber (12) (1 ml/chamber) and allowed to migrate for $3 \mathrm{~h}$ at $37^{\circ} \mathrm{C}$ toward one of several chemotactic factors. In the third case, cells were obtained after they had responded to chemotactic factor and appeared in the lower compartment of the chemotactic chamber. In each case, cells were washed twice to remove media and chemotactic factor and tested in the appropriate assay. The three cell preparations represent $(a)$ control cells, $(b)$ cells exposed to chemotactic factor, and $(c)$ cells that had actually migrated through a membrane in response to the same concentration of chemotactic factor.

Guinea pig peripheral blood and peritoneal exudate PMN were obtained from male, outbred, Hartley guinea pigs $4 \mathrm{~h}$ after an intraperitoneal injection of $10 \mathrm{ml}$ of $50 \%$ caseinsaturated Eagle's Minimum Essential Media (Casein supplied by Fischer Scientific Co., Pittsburgh, Pa.). Casein preparations were centrifuged at $20,000 \mathrm{~g}$ for $20 \mathrm{~min}$ and filtered through a $0.22-\mu \mathrm{m}$ pore-size filter to remove any particulate before injection. Peritoneal exudate cells were obtained by lavage using $100 \mathrm{ml}$ of $\mathrm{HBSS}$ with $5 \mathrm{U}$ of heparin $/ \mathrm{ml}$ to wash the peritoneal cavity. The fluids were centrifuged and the cell pellet washed and resuspended to $1 \times 10^{7}$ cells $/ \mathrm{ml}$. Differential counts on these cells indicated that they contained $>90 \%$ neutrophils. Peripheral blood was obtained by cardiac puncture from the same animal after peritoneal lavage. Blood was heparinized and PMN were prepared by Ficoll-Hypaque centrifugation followed by Plasmagel sedimentation of erythrocytes. Residual exythrocytes were lysed by a 30-s treatment with $4^{\circ} \mathrm{C}$ distilled water, and cells were resuspended to $1 \times 10^{7}$ cells $/ \mathrm{ml}$. Differential counts showed these preparations to contain $>90 \%$ PMN. In each case, peritoneal exudate cells were treated for $30 \mathrm{~s}$ with distilled water for comparison with peripheral blood PMN where residual erythrocytes were similarly lysed.

Chemotactic factors. Three types of chemotactic factors were used in this study. The first was a mixture containing $50 \%$ casein-saturated minimum essential media and $10 \%$ fresh autologous normal serum. This preparation proved to be a potent chemotactic mixture and was the primary chemotactic factor used to attract large numbers of cells through the chemotaxis membrane. This mixture was found to be both chemotactic and chemokinetic as determined by titration experiments using the leading front assay for chemotaxis (13) and by determining that maximal migration in the presence of a positive chemotactic gradient far exceeded the maximal chemokinetic response observed with no gradient present. The second factor used was a partially purified preparation of chemotactic C5 fragment obtained from fresh serum after its activation with zymosan $(20 \mathrm{mg} / \mathrm{ml}$ zymosan for $60 \mathrm{~min}$ at $37^{\circ} \mathrm{C}$ ). The chemotactic $\mathrm{C} 5$ fragment was obtained by passage of activated human serum over a Sephadex G-75 column. The low molecular weight fractions with chemotactic activity were concentrated by ultrafiltration, using a membrane permeable to molecules of $<2,000 \mathrm{~mol} \mathrm{wt}$. This preparation was chemotactic for human PMN and its activity was $95 \%$ inhibitable with anti-human C5. C5a was titrated for optimal chemotaxis in a quantitative chemotaxis assay (11) and used at this concentration. Finally, in some studies a preparation of the synthetic chemotactic peptide f-MetLeu-Phe (kindly provided by Dr. Richard Freer of the Medical
College of Virginia) was used at a concentration of $10 \mathrm{nM}$, which proved to be optimal for migration. In all cases, preexposure of PMN for $1 \mathrm{~h}$ to the concentrations of each chemotactic factor used in the study, followed by removal of the factor, deactivated these cells to the same factor later, as indicated by $>50 \%$ inhibition in a quantitative chemotaxis assay (11).

Chemiluminescence assay. PMN chemiluminescence was assayed as previously described in phosphate-buffered saline, pH 7.4, using zymosan that had been opsonized with fresh normal human serum as a stimulant (14). When guinea pig PMN were used, zymosan was opsonized in the same manner with fresh guinea pig serum. PMN $\left(5 \times 10^{6}\right)$ were added in the dark to $2 \mathrm{mg}$ of zymosan in a final volume of $1 \mathrm{ml}$. In some instances soluble factors were used to stimulate chemiluminescence, including $100 \mu \mathrm{g} / \mathrm{ml}$ Con A and $1.0 \mu \mathrm{g} / \mathrm{ml}$ phorbol myristate acetate (PMA) (Sigma Chemical Co., St. Louis, Mo.). When soluble stimuli were used, $10 \mathrm{nM}$ luminol (Sigma Chemical Co.) was added to the mixture (15). $5 \mathrm{mg} / \mathrm{ml}$ PMA was prepared in dimethyl sulfoxide and diluted to the appropriate concentration in media just prior to testing. Assays were performed in 18-h dark-adapted Beckman poly $Q$ vials (Beckman Instruments, Inc., Fullerton, Calif.), and analyzed in a nonrefrigerated Nuclear-Chicago $\beta$-scintillation counter (Nuclear-Chicago Corp., Des Plaines, Ill.) used out of coincidence with a window setting of 0,10 . Chemiluminescence, unless otherwise stated, was measured using 1-min counts at $6-\mathrm{min}$ intervals for a minimum of $49 \mathrm{~min}$. In each case, data are presented either as the chemiluminescence curve obtained or as the integrated area under the curve.

Superoxide anion assay. Superoxide anion generation was measured by the reduction of cytochrome $c$ (16). Cells to be tested were washed and resuspended in HBSS without phenol red to $1 \times 10^{7} \mathrm{PMN} / \mathrm{ml}$. In some cases $\mathrm{PMN}$ were stimulated with normal serum-opsonized zymosan $(2 \mathrm{mg}$ ) by mixing zymosan with $5 \times 10^{6} \mathrm{PMN}$, centrifuging for $45 \mathrm{~s}$ at $1,000 \mathrm{~g}$, and resuspending in $1.5 \mathrm{ml}$ of an $80-\mu \mathrm{M}$ cytochrome $c$ solution prepared in HBSS without phenol red. Samples were then incubated for $5 \mathrm{~min}$ at $37^{\circ} \mathrm{C}$. Unstimulated samples consisted of $5 \times 10^{6} \mathrm{PMN}$ incubated in $1.5 \mathrm{ml}$ of $80 \mu \mathrm{M}$ cytochrome $c$, for $30 \mathrm{~min}$ at $37^{\circ} \mathrm{C}$. The longer incubation period was essential for unstimulated cells to achieve a measurable release of superoxide anion. Superoxide anion release was assessed by determining the reduction of cytochrome $c$ using spectrophotometric analysis at an optical density of $550 \mathrm{nM}$. The amount of cytochrome $c$ reduced in each case was determined using a molar extinction coefficient of $2.1 \times 10^{4}$ and expressing the result as nanomoles of cytochrome $c$ reduced per $10^{6} \mathrm{PMN}$

Bactericidal assay. Bactericidal activity was assayed as previously described (17), using Escherichia coli $\mathrm{K} 12$ as a target microorganism. Mixtures containing $\sim 2.5 \times 10^{8}$ bacteria, $0.3 \mathrm{ml}$ of opsonin (fresh normal serum diluted 1:3), and $5 \times 10^{6} \mathrm{PMN}$ were adjusted to $1 \mathrm{ml}$ with $\mathrm{HBSS}$ and used to assay PMN bactericidal activity. Mixtures were sampled after $0-, 30-, 60-$, and 90 -min incubations at $37^{\circ} \mathrm{C}$ by removing $0.001 \mathrm{ml}$ of the mixture with a calibrated loop, diluting this in $1 \mathrm{ml}$ distilled water and subsequently mixing $0.1 \mathrm{ml}$ of this suspension with Bacto antibiotic medium 2 agar (Difco Laboratories, Detroit, Mich.) in a pour plate. Pour plates were incubated overnight and the number of viable bacteria determined by colony counts.

Determination of IgG and complement receptor positive $P M N$. PMN bearing IgG receptors were quantitated by both the rosette technique (17) and fluorescence microscopy, using the method of Winfield et al. (18). PMN bearing complement receptors were quantitated using the rosette technique. Rosette assays for IgG receptors were performed with bovine 
erythrocytes coated with rabbit IgG antibovine erythrocyte antibodies (17). Complement receptor-bearing cells were determined using sheep erythrocytes coated with rabbit IgM anti-sheep erythrocyte antibody and human complement that had been absorbed with sheep erythrocytes (17). PMN $\left(2 \times 10^{6}\right.$ in $\left.0.2 \mathrm{ml}\right)$ were mixed with $0.2 \mathrm{ml}$ of a $1 \%$ solution of each of the erythrocyte preparations, centrifuged at $800 \mathrm{~g}$ for $4 \mathrm{~min}$, and incubated at room temperature for $15 \mathrm{~min}$. Cells were gently resuspended and the number of rosettes (three or more erythrocytes bound to a PMN) were quantitated in a hemocytometer and expressed as a percent of the total PMN present. Fewer than 3\% rosettes were observed when uncoated bovine erythrocytes and uncoated or IgMcoated sheep erythrocytes were used.

IgG receptor-bearing PMN were also quantitated using a modification of the method of Winfield et al. (18). Preparations of rabbit b4 allotype IgG and rabbit anti-b4 IgG were prepared by DEAE ion exchange chromatography (18). PMN $\left(2 \times 10^{6}\right)$ were incubated with $0.08 \mathrm{mg}$ of rabbit b4 IgG at $4^{\circ} \mathrm{C}$ for $30 \mathrm{~min}$. Cells were then washed twice and incubated for $30 \mathrm{~min}$ at $4^{\circ} \mathrm{C}$ with $40 \mu \mathrm{l}$ of anti-b4 IgG which had been titrated to give optimal binding. Cells were again washed twice and subsequently incubated with fluorescein isothiocyanate-conjugated goat anti-rabbit IgG for $30 \mathrm{~min}$ at $4^{\circ} \mathrm{C}$.
After an additional two washes, cells were observed by fluorescence microscopy and the number of positive cells quantitated. Fluorescence was inhibited by aggregated human IgG and no reduction in fluorescence was observed following absorption of the rabbit b4 or anti-b4 with human erythrocytes.

\section{RESULTS}

Enhanced PMN chemiluminescence after chemotaxis and chemotactic factor exposure. PMN from five individuals were incubated at $37^{\circ} \mathrm{C}$ for $3 \mathrm{~h}$ in either $5 \%$ FCS or a chemotactic factor preparation containing 5\% FCS; or the PMN in 5\% FCS were allowed to migrate through a $5-\mu \mathrm{m}$ pore-size membrane to the lower compartment of the enlarged chemotaxis chamber in response to chemotactic factor. The three cell preparations were then washed free of chemotactic factor and tested for chemiluminescence in a zymosanstimulated system. Fig. 1 shows the mean chemiluminescence for each cell preparation using three dif-
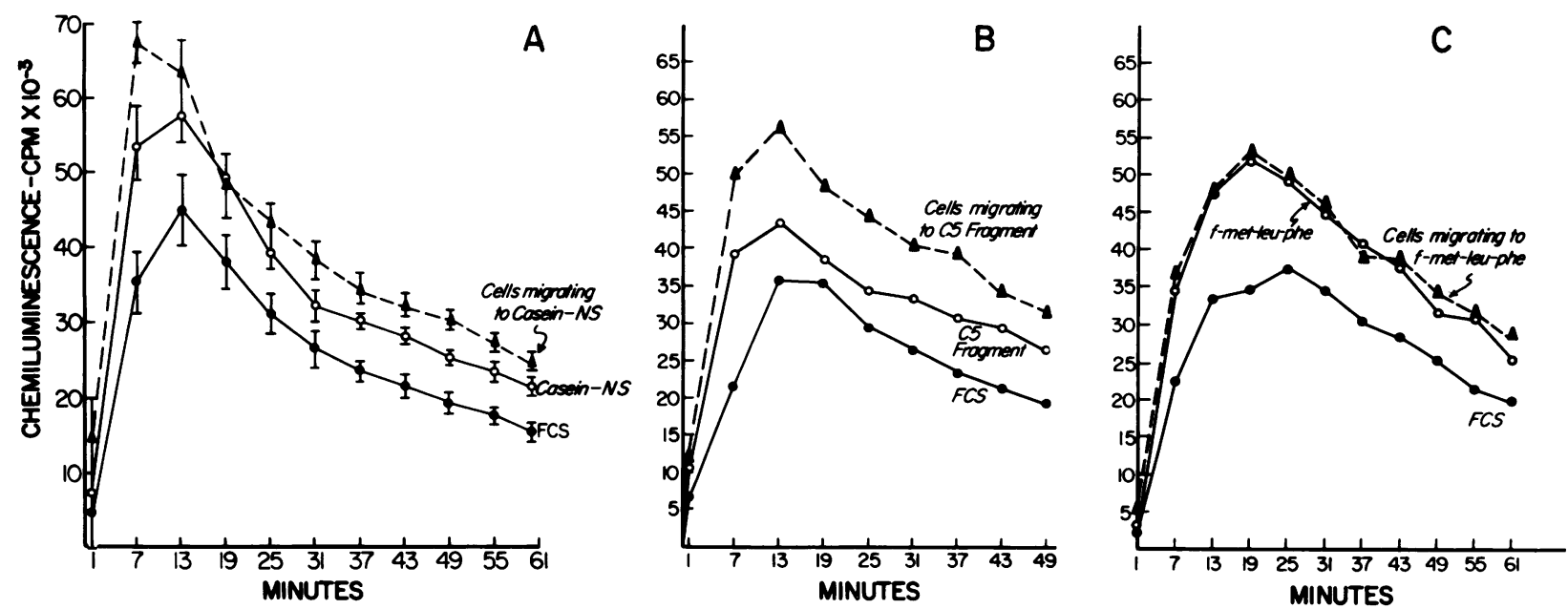

FIgure 1 (A) Chemiluminescence of PMN responding to a chemotactic mixture of casein and fresh autologous serum. Results on the left show the mean \pm SEM chemiluminescence with five different subjects. Results with cells incubated in FCS $(\bullet)$, in the chemotactic mixture $(0)$, and cells that have been collected from the lower compartment of the chemotaxis chamber $(\boldsymbol{\Delta})$ are shown. Integrated areas under the curves gave the same order of activity (mean integrated area for FCS-treated cells $=1.67 \times 10^{6}$, for chemotactic factor-treated cells $=1.85 \times 10^{6}$, for cells migrating to chemotactic factor $\left.=2.39 \times 10^{6}\right)$. Statistical analysis of the areas under the curves by paired $t$ test analysis showed that both cells treated with chemotactic factor and those that have migrated to chemotactic factor have a significantly greater chemiluminescence than cells incubated in FCS alone $(P<0.05)$. Furthermore, PMN that have migrated to chemotactic factor also showed significantly greater chemiluminescence than cells incubated in chemotactic factor $(P$ $<0.05)$. (B) C5a was used as a chemotactic factor and PMN from three subjects were compared. The mean results are shown. All three subjects gave a similar pattern of chemiluminescence and by comparison of both peak chemiluminescence and area, FCS $<$ C5a-treated cells $<$ cells that had migrated to C5a. The mean integrated areas under the curves for all three subjects are as follows: $\mathrm{FCS}=1.25 \times 10^{6}$, C5a-treated $=2.01 \times 10^{6}$, cells migrating to $\mathrm{C} 5 \mathrm{a}=2.37 \times 10^{6}$. $(\mathrm{C})$ Zymosan-stimulated chemiluminescence of PMN responding to f-Met-Leu-Phe as compared with controls. Data shown are the means of data obtained with three different subjects. In all three subjects both the peak chemiluminescence and integrated areas under the curves were markedly higher than controls for PMN incubated with or migrating to f-Met-Leu-Phe. Mean integrated areas under the curves for the three subjects were as follows: FCS $=1.69 \times 10^{6}$, incubated with $\mathrm{f}$-Met-Leu-Phe $=2.28 \times 10^{6}$, cells migrating to $\mathrm{f}$-Met-Leu-Phe $=2.353 \times 10^{6}$. 
ferent chemotactic stimuli, including a casein-autologous serum mixture, C5a, and f-Met-Leu-Phe. As shown, cells treated with any of the chemotactic factors showed markedly enhanced chemiluminescence when compared with the control cells incubated with FCS. Furthermore, the preparation of PMN that had actually migrated through the $5-\mu \mathrm{m}$ pore-size membrane in response to chemotactic factor showed in most cases even greater chemiluminescence than cells simply incubated in chemotactic factor. This difference was consistent in all cell preparations and was apparent in both the peak chemiluminescence as well as the integrated areas under the chemiluminescence curves. The mean integrated areas for each set of experiments are indicated in the legend for Fig. 1. In the absence of zymosan, no difference in resting (unstimulated) chemiluminescence was observed. Furthermore, in tests on six different cell preparations, no significant difference in the stimulated chemiluminescence was observed between PMN tested immediately after cell isolation $(51,865 \pm 5,731)$ and those that had been incubated in FCS for $3 \mathrm{~h}$ at $37^{\circ} \mathrm{C}(50,289 \pm 6,081)$.
Similar chemiluminescence studies were performed substituting soluble Con A and PMA for the insoluble zymosan stimulant in a system containing $10 \mathrm{nM}$ luminol. As shown in Table I, a similar enhanced chemiluminescence was observed in PMN preincubated in chemotactic factor (casein-autologous serum mixture) and subsequently washed. Likewise, an even greater chemiluminescence was observed in PMN allowed to migrate to chemotactic factor. Data in Table I were obtained using $100 \mu \mathrm{g} / \mathrm{ml} \mathrm{Con} \mathrm{A} \mathrm{and} 1 \mu \mathrm{g} / \mathrm{ml}$ PMA. In all cases, the chemiluminescence of PMN migrating to chemotactic factor was greater than PMN incubated in chemotactic factor, which was greater than PMN incubated in media alone. This order was independent of the concentration of Con A or PMN, because this same order was maintained at 10or 100-fold lower concentrations, although the peak response at lower concentrations was proportionally decreased.

Duration of enhanced chemiluminescence. Whether the enhanced chemiluminescence of PMN resulting from exposure to chemotactic factor repre-

TABLE I

Chemiluminescence Activity of Control PMN, Chemotactic Factor-treated PMN, and PMN Prepared by Chemotaxis after Stimulation with Con A and PMA

\begin{tabular}{|c|c|c|c|}
\hline \multirow[b]{2}{*}{ Experiments } & \multicolumn{3}{|c|}{ Peak chemiluminescence response with each cell preparation } \\
\hline & Control & $\begin{array}{l}\text { Incubated with } \\
\text { chemotactic } \\
\text { factor* }\end{array}$ & $\begin{array}{l}\text { Prepared by } \\
\text { chemotaxis }\end{array}$ \\
\hline & \multicolumn{3}{|c|}{$c p m$} \\
\hline \multicolumn{4}{|c|}{ Stimulated with Con At } \\
\hline 1 & 419,994 & 431,382 & 627,801 \\
\hline 2 & 198,414 & 348,403 & 768,081 \\
\hline 3 & 49,212 & 76,096 & 189,428 \\
\hline 4 & 70,588 & 102,499 & 131,151 \\
\hline 5 & 58,954 & 63,820 & 72,584 \\
\hline 6 & 246,717 & 764,440 & 768,995 \\
\hline 7 & 54,811 & 59,027 & 65,566 \\
\hline 8 & 51,406 & 105,862 & 249,575 \\
\hline Mean \pm 1 SD $\S$ & $143,762 \pm 135,129$ & $243,941 \pm 253,784$ & $359,147 \pm 309,025$ \\
\hline \multicolumn{4}{|c|}{ Stimulated with PMA } \\
\hline 1 & 75,257 & 118,228 & 156,107 \\
\hline 2 & 223,898 & 306,409 & 372,302 \\
\hline 3 & 98,213 & 277,268 & 562,060 \\
\hline 4 & 135,055 & 247,104 & 352,609 \\
\hline 5 & 223,693 & 457,570 & 762,580 \\
\hline 6 & 89,254 & 199,926 & 219,653 \\
\hline 7 & 463,145 & 768,045 & 781,136 \\
\hline 8 & 289,955 & 696,917 & 749,417 \\
\hline Mean \pm 1 SD $\S$ & $199,809 \pm 131,406$ & $383,933 \pm 236,489$ & $494,483 \pm 253,177$ \\
\hline
\end{tabular}


sents a permanent elevation in PMN responsiveness or a transient condition was investigated. A portion of PMN that had migrated to the casein-autologous serum mixture or chemotactic C5 fragment and PMN that had been incubated in 5\% FCS for $3 \mathrm{~h}$ were washed, counted, resuspended in phosphate-buffered saline, and tested in the chemiluminescence assay. Remaining cells were washed and resuspended in 5\% FCS for $2.5 \mathrm{~h}$ at $37^{\circ} \mathrm{C}$. Subsequently, cells were again washed, counted, and resuspended to $1 \times 10^{7} \mathrm{PMN} / \mathrm{ml}$ in phosphate-buffered saline. Each preparation was then tested in the zymosan-stimulated chemiluminescence assay a second time. Those cells that had responded to chemotactic factor still yielded a significantly greater chemiluminescence than did control cells, as indicated in the representative results of three experiments with two chemotactic preparations shown in Fig. 2. Furthermore, both cell preparations gave a response comparable to that obtained prior to the additional 2.5-h incubation in media alone. This prolonged activation was also observed in PMN simply incubated in the casein-autologous serum mixture or chemotactic C5 fragment, and indicates that this enhancement was maintained for at least $2.5 \mathrm{~h}$.

Superoxide anion release from chemotactic factorstimulated PMN. Stimulation of PMN with opsonized zymosan not only results in chemiluminescence, but also in an increased production and secretion of superoxide anion. Studies were designed to determine whether P.MN stimulated with chemotactic factor and extensively washed showed enhanced production of superoxide anion. The same three groups of cells were prepared, washed, and tested for superoxide anion generation in both zymosan-stimulated and unstimulated assays. The chemotactic mixture used was the casein-autologous serum mixture. Table II shows the results of control and chemotactic factor-stimulated PMN from several different cell donors. It is evident that the secretion of superoxide anion as measured by cytochrome $c$ reduction is significantly elevated both in P.MN incubated with this chemotactic mixture and in those that have migrated through the 5 - $\mu \mathrm{m}$ poresize membrane in response to chemotactic factor. This increase in superoxide anion release was apparent both in the presence and absence of opsonized zymosan. The observed reduction of cytochrome $c$ in these experiments was attributed to the production of superoxide anion since cytochrome $c$ reduction was totally abrogated by the addition of $50 \mu \mathrm{g}$ of superoxide dismutase.

Enhanced bactericidal activity by chemotactic factor-stimulated neutrophils. Since both chemiluminescence and superoxide anion production have been linked with bacterial killing $(19,20)$, experiments were performed to determine whether chemotactic factor enhanced PMN bactericidal activity. PMN from five donors were prepared and treated for $3 \mathrm{~h}$ at $37^{\circ} \mathrm{C}$ with either $5 \%$ FCS or the casein-autologous serum mixture; or the PMN were allowed to migrate in response to the chemotactic preparation. These cell

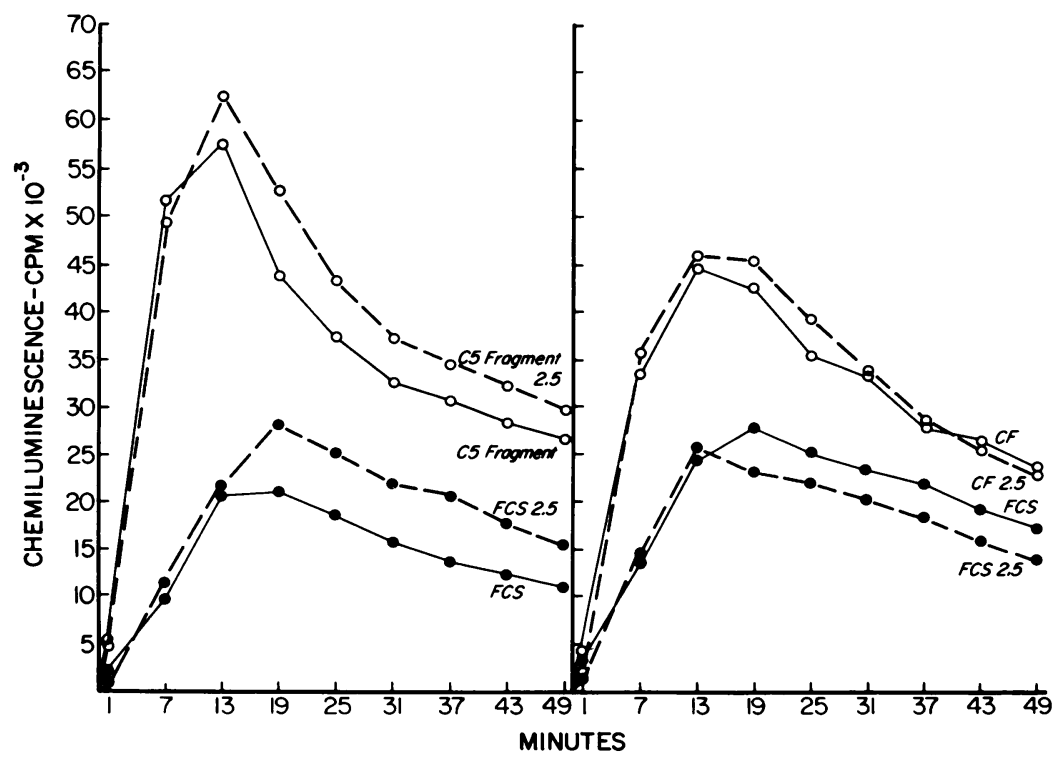

FIGURE 2 Maintenance of PMN activation in the absence of chemotactic factor. The left side of the figure shows the chemiluminescence of P.MN that have migrated to chemotactic C5 fragment (O), and the right side, that of PMN that have migrated to the casein-autologous serum mixture (O) for $3 \mathrm{~h}$. Both are compared with PMN incubated in FCS (O). Solid lines show the results of PMN tested immediately after the migration to chemotactic factor or incubation with FCS and dashed lines indicate the response after cells were washed and incubated an additional $2.5 \mathrm{~h}$ in $10 \%$ FCS in the absence of chemotactic factor. 
TABLE II

Superoxide Anion Generation by PMN Activated with Chemotactic Factor

\begin{tabular}{|c|c|c|c|}
\hline \multirow[b]{2}{*}{ Experiments } & \multicolumn{3}{|c|}{$\begin{array}{l}\text { Release of superoxide anion from PMN } \\
\text { preparations in nanomoles of cytochrome } c \text { - } \\
\text { reduced } / 10^{6} \text { PMN }\end{array}$} \\
\hline & Control & $\begin{array}{l}\text { Incubated } \\
\text { with } \\
\text { chemotactic } \\
\text { factor* }\end{array}$ & $\begin{array}{l}\text { Prepared by } \\
\text { chemotaxis }\end{array}$ \\
\hline \multicolumn{4}{|l|}{ Unstimulated } \\
\hline 1 & 2.3 & 5.2 & 6.6 \\
\hline 2 & 2.8 & 3.8 & 6.6 \\
\hline 3 & 7.6 & 7.6 & 8.5 \\
\hline 4 & 3.8 & 10.4 & 8.1 \\
\hline 5 & 3.3 & 9.0 & 8.6 \\
\hline 6 & 10.0 & 11.9 & 15.2 \\
\hline Mean \pm SD $\ddagger$ & $5.0 \pm 3.1$ & $8.0 \pm 3.1$ & $8.9 \pm 3.2$ \\
\hline \multicolumn{4}{|c|}{ Zymosan-stimulated } \\
\hline 1 & 22.8 & 38.1 & 25.7 \\
\hline 2 & 39.0 & 44.7 & 48.5 \\
\hline 3 & 30.4 & 43.8 & 47.6 \\
\hline 4 & 45.7 & 47.6 & 46.6 \\
\hline 5 & 32.3 & 43.8 & 40.4 \\
\hline 6 & 43.8 & 40.9 & 41.9 \\
\hline 7 & 16.6 & 40.0 & 35.2 \\
\hline Mean \pm SD $\ddagger$ & $32.9 \pm 10.8$ & $42.7 \pm 3.2$ & $40.8 \pm 8.2$ \\
\hline
\end{tabular}

* The chemotactic factor used was a casein-autologous serum mixture.

\$ Statistical analysis gave a $P<0.05$ for comparison of control cells to chemotoactic factor-treated cells and those migrating to chemotactic factor in both zymosan-stimulated and unstimulated experiments. The difference between chemotactic factor-treated cells and those migrating to chemotactic factor was not significant with either unstimulated or stimulated PMN by the paired $t$ test.

preparations were then tested for bactericidal activity using $E$. coli as a target microorganism. As shown in Fig. 3, the bactericidal activity of PMN exposed to chemotactic factor and of those that migrated in response to chemotactic factor is significantly greater ( $P<0.05$ by a paired $t$ test analysis) than that of control PMN. Although cells that migrated through the 5- $\mu \mathrm{m}$ pore-size membrane show a slightly greater bactericidal activity than cells simply incubated in chemotactic factor, the difference was not statistically significant by a paired $t$ test with this sample size.

Surface receptor analysis. It is feasible that modulation of surface opsonic receptors could account for the differences in the PMN responses described here. $\mathrm{PMN}$ preparations incubated for $3 \mathrm{~h}$ at $37^{\circ} \mathrm{C}$ in either $5 \%$ FCS or the casein-autologous serum mixture, as well as PMN that had migrated to this chemotactic preparation, were tested for $\mathrm{Fc}$ and complement re- ceptor positive cells. Table III shows the comparative results of tests for $\mathrm{Fc}$ receptor positive cells using both the erythrocyte antibody-rosetting technique and the fluorescence technique. The table also shows results of tests for complement receptor positive cells assayed by erythrocyte-IgM antibody-complement rosette formation. No significant difference in the percentage of cells bearing $\mathrm{Fc}$ or complement receptors was observed among any of the three preparations.

Enhanced chemiluminescence in vivo by stimulated guinea pig peritoneal exudate neutrophils. To equate our in vitro findings with an in vivo model, guinea pigs were injected intraperitoneally with a 50\%saturated solution of casein in minimum essential media. $4 \mathrm{~h}$ later, PMN were removed from the peritoneal cavity, washed, and compared by chemiluminescence to peripheral blood PMN isolated from the same guinea pig. Results (Fig. 4) indicate that PMN responding in vivo to an inflammatory stimulus show enhanced chemiluminescence compared with PMN obtained from the peripheral blood of the same guinea pig. These data support the in vitro evidence presented previously and indicate that, in vivo, PMN migrating to an

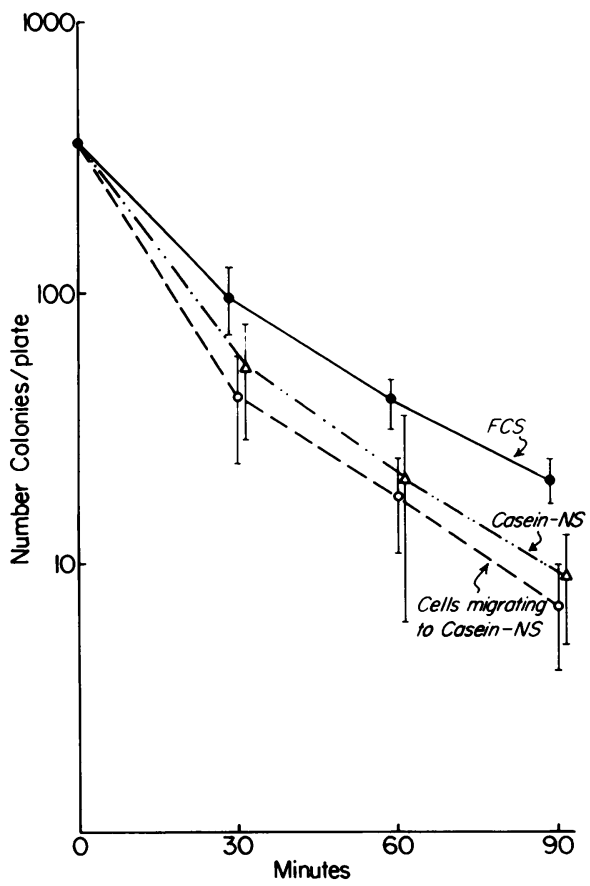

FIGURE 3 Enhancement of PMN bactericidal activity as a result of chemotaxis and chemotactic factor exposure. Results show the mean \pm 1 SD at each point for $P M N$ from five different subjects. Killing curves are shown for FCS-treated PMN (๑), chemotactic factor- (casein-autologous serum) treated cells $(\triangle)$, and cells that had migrated to the casein-autologous serum mixture (O). Both cells incubated with chemotactic factor and those that had migrated to chemotactic factor showed significantly greater bacterial killing $(P<0.05)$ at 30 , 60 , and $90 \mathrm{~min}$ by paired $t$ test. 
inflammatory foci show an enhanced stimulated chemiluminescence similar to those responding to a chemotactic stimulus in vitro.

\section{DISCUSSION}

Many previous studies have shown that the direct addition of chemotactic factors to PMN preparations can stimulate neutrophil function and metabolism. These changes include the following: $(a)$ chemotactic formylated peptides stimulate neutrophil chemiluminescence $(2) ;(b)$ exposure to C5a causes neutrophil aggregation (3); $(c)$ bacterial derived chemotactic factors, formyl-methionine-alanine, and trypsin-activated complement increase intracellular levels of cGMP (4); (d) f-Met-Leu-Phe and C5a increase assembly of microtubules $(5,6)$; (e) C5a, C3a, C567 (7), and formylated peptides (21) stimulate neutrophil degranulation (7); $(f)$ f-Met-Leu-Phe, C5a, and bacterial derived chemotactic factors increase cell adherence $(6,8)$; and $(g) \mathrm{f}$-Met-Leu-Phe stimulates neutrophil production of superoxide anion $(6,9)$. The present study demonstrates that PMN that have been exposed to or have migrated to the chemotactic mixture of casein and autologous serum are "activated" as indicated by enhanced chemiluminescence, superoxide anion production, and bactericidal activity. It is important to note that in this study cells were washed free of chemotactic factor in the media before testing since many of the previous studies mentioned demonstrate the effect of direct addition of chemotactic factor to P.MN preparations. Although washing the cells before testing removes chemotactic factor in the media, it

TABLE III

Comparison of Surface Fc and Complement Receptors with Various Preparations of PMN

\begin{tabular}{|c|c|c|c|}
\hline \multirow[b]{2}{*}{$\begin{array}{l}\text { Receptor } \\
\text { assay }\end{array}$} & \multicolumn{3}{|c|}{ Per cent positive PMN in each cell preparation* } \\
\hline & Control & $\begin{array}{l}\text { Incubated with } \\
\text { chemotactic } \\
\text { factor }\end{array}$ & $\begin{array}{l}\text { Cells migrating } \\
\text { to chemotactic } \\
\text { factort }\end{array}$ \\
\hline EA rosette $(21) \S$ & $79 \pm 14$ & - & $73 \pm 24$ \\
\hline EAC rosette $(15) \S$ & $67 \pm 13$ & - & $70 \pm 21$ \\
\hline $\begin{array}{l}\text { Fluorescent Fc }(5) \S \\
\text { technique }\end{array}$ & $97 \pm 2$ & $9.5 \pm 2$ & $98 \pm 2$ \\
\hline
\end{tabular}

* Results are expressed as the mean percent positive cells $\pm 1 \mathrm{SD}$.

$\$$ Chemotactic factor used was a mixture of casein and autologous serum. Statistical analysis by paired $t$ test showed no significant difference between control and chemotactic factortreated preparations or control PMN compared with cells migrating to chemotactic factor.

$\$$ Numbers in parentheses equal the number of different donor cell preparations tested. EA, erythrocyte antibody; EAC, erythrocyte-IgM antibody-complement.
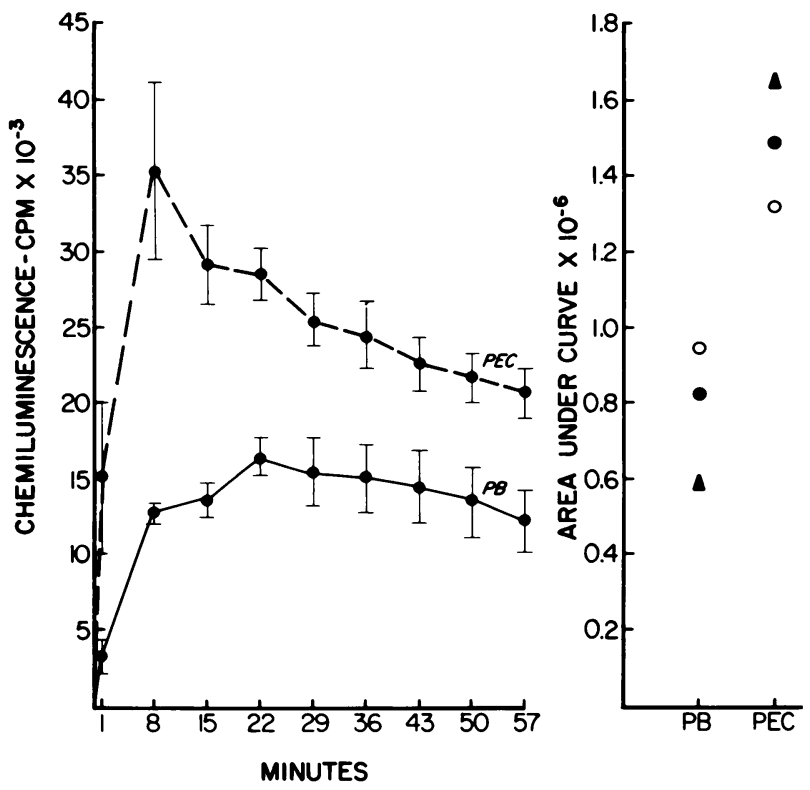

FIGURE 4 Chemiluminescence of guinea pig peripheral blood (PB) PMN compared with casein-stimulated peritoneal exudate (PEC) PMN from the same animal. Mean \pm SEM chemiluminescence on three different guinea pig preparations are shown on the left and integrated areas for each paired preparation are shown on the right.

does not mean that all chemotactic factor has been removed from the system since some may be bound to cells or internalized. Although the effect of bound chemotactic factor on the assays performed is unknown, it has been shown that, at least in the chemiluminescence assay system, the response of PMN to the chemotactic factor f-Met-Leu-Phe peaks at $2 \mathrm{~min}$ and drops off exponentially thereafter (2). Because PMN in this study were incubated for $3 \mathrm{~h}$ with chemotactic factor, the chemiluminescence of P.MN stimulated by chemotactic factor would have been far beyond its peak. In this study, enhanced stimulated chemiluminescence occurred with all tested chemotactic factors, including chemotactic C5 fragment, f-Met-Leu-Phe, and a mixture of casein and fresh autologous serum. Enhancement was generally greater in cells that had actually migrated through a $5-\mu \mathrm{m}$ pore-size chemotaxis membrane, than in those simply incubated for the same time in chemotactic factor. Additional studies (Fig. 2) show that PMN responding to chemotactic factor (either the caseinautologous serum mixture or chemotactic C5 fragment) maintained this enhanced chemiluminescence for at least $2.5 \mathrm{~h}$ in the absence of chemotactic factor. It is possible that the differences observed here between control P.MN and those migrating in response to a chemotactic factor arose from the isolation of a more active subpopulation of PMN moving through the membrane. Such a subpopulation of $F_{C}$ receptor posi- 
tive granulocytes has been described in a previous report by Klempner and Gallin (22). In our study, however, comparisons have not shown a significant difference among the number of $\mathrm{Fc}$ or complement receptor-bearing PMN in control preparations, chemotactic factor-treated preparations, or cells prepared by chemotaxis (Table III).

Because enhanced chemiluminescence of PMN exposed to chemotactic factor persisted for at least $2.5 \mathrm{~h}$ in the absence of chemotactic factor, it may be that activation itself involves some more permanent biologic changes, possibly in cell metabolism, cytoskeleton, or membrane structure. This would seem to preclude simply a short-term shift in intracellular regulators such as a cAMP or cGMP since elevated levels of cyclic nucleotides resulting from exposure of PMN to chemotactic factors and chemotactic modulators generally decrease within $1 \mathrm{~h}(4)$.

Previous studies $(6,8)$ have shown that chemotactic factors increase cell adherence, which could cause increased chemiluminescence and superoxide anion generation in systems stimulated with zymosan. Similarly, adherence is also essential to the bactericidal assay system. Although increased cell adherence in chemotactic factor-activated PMN may affect assays involving zymosan and bacteria, it should not affect assays mediated by soluble stimuli. Since chemotactic factoractivated PMN show enhanced chemiluminescence in response to both Con A and PMN (Table I), it is apparent that adherence is not the only mechanism involved in this enhancement. Likewise, experiments measuring superoxide anion generation by chemotactic factor-activated PMN in the absence of zymosan also indicate that these cells do not need a particulate stimulus to show enhanced superoxide anion production.

Studies by Gallin et al. (10) have shown that PMNdegranulating agents such as PMA, Con A, and the calcium ionophore A23187 increase PMN adherence and affect chemotactic factor binding under the proper conditions. These agents may act by exposing new membrane at the cell surface as a result of the exocytosis of specific granules, a process also known to occur when neutrophils are exposed to chemotactic factor $(7,21)$. Whether or not such a phenomenon exposes new opsonic receptors or granule-associated oxidase activity (23) is unknown. Such alterations in the cell membrane could explain both increased chemiluminescence and superoxide anion production in the chemotactic factor-activated neutrophil. Although exocytosis of granules may expose new membrane, the data in Table III indicate that the percentage of $\mathrm{Fc}_{\mathrm{c}}$ and complement receptor positive cells in control and chemotactic factor-treated cells does not differ. This is of interest, but does not discount a change in the number of receptors per cell.
It is apparent from Fig. 4 that the migration of PMN to the casein-stimulated peritoneal cavity of the guinea pig results in a population of PMN with enhanced chemiluminescence much like that observed in our in vitro studies with human PMN. This enhancement in vivo supports the contention that chemotactic factor activation of PMN represents an important mechanism of increasing host defense at specific locations where these factors are generated.

It is of interest to note the similarity between studies with activated or elicited macrophages and the studies presented here with PMN. Recent studies by Johnston et al. (16) demonstrate that both elicited and activated peritoneal macrophages show enhanced stimulated superoxide anion release as compared with resident macrophages. Other investigators (24) have found that activated macrophages give an enhanced chemiluminescence when stimulated with opsonized particles. It appears from our study that peripheral blood PMN may be stimulated by chemotactic factor in vitro to show both enhanced chemiluminescence and superoxide anion generation. Furthermore, caseinelicited PMN obtained from the peritoneal cavity of guinea pigs show enhanced chemiluminescence and in this way resemble activated or elicited macrophages.

A recent study by Cross and Lowell (25) showed that stimulated lymphocyte supernates also increase the bactericidal activity of PMN. Such an activation could be due to the presence of PMN chemotactic factors-known to be present in such preparations (26) - which could activate PMN in a manner similar to that observed here with other chemotactic factors. In addition, a report by Issekutz et al. (27), published during the course of our study, indicates that PMN bactericidal activity for Staphylococcus aureus, E. coli, and Streptococcus faecalis is increased by chemotactic factor exposure. Our study furthers their work and shows that (a) zymosan-, PMA-, and Con A-stimulated chemiluminescence, as well as zymosan-stimulated and unstimulated superoxide anion production, are increased in PMN that have migrated to or are exposed to chemotactic factor in a system where cells are washed free of exogenous chemotactic factor; $(b)$ this enhanced activity persists for at least $2.5 \mathrm{~h}$ in the absence of chemotactic factor; $(c)$ enhanced PMN chemiluminescence is also observed with casein-elicited guinea pig PMN in vivo; and $(d)$ enhanced PMN function due to chemotactic factor exposure is not the result of an increased number of $\mathrm{Fc}_{\mathrm{c}}$ or complement receptor positive PMN, as determined by the methods employed here.

\section{ACKNOWLEDGMENTS}

We wish to thank Drs. Kenneth Tung and Aneiko Meng for providing guinea pig polymorphonuclear leukocytes essential to this study, Dr. Richard Freer of the Medical College of 
Virginia for providing us with f-Met-Leu-Phe, Dr. Kay Knight of the University of Illinois for providing us with anti-b4 allotype antisera, and Carol Arnold for her excellent secretarial assistance.

This study was supported by a grant from the National Cancer Institute, CA 20819; the Department of Health, Education, and Welfare; and the Arthritis Foundation.

\section{REFERENCES}

1. Wilkinson, P. C. 1974. Chemotaxis and Inflammation. Churchill Livingstone, Edinburgh, UK.

2. Hatch, G. E., D. E. Gardner, and D. E. Menzel. 1978. Chemiluminescence of phagocytic cells caused by $N$. formylmethionyl peptides. J. Exp. Med. 147: 182-195.

3. O'Flaherty, J. T., D. L. Kreutzer, and P. A. Ward. 1977. Neutrophil aggregation and swelling induced by chemotactic agents. J. Immunol. 119: 232-239.

4. Hatch, G. E., W. K. Nichols, and H. R. Hill. 1977. Cyclic nucleotide changes in human neutrophils induced by chemoattractants and chemotactic modulators. J. Immunol. 119: 450-456.

5. Gallin, J. I., E. K. Gallin, H. L. Malech, and E. B. Cramer. 1978. Structural and ionic events during leukocyte chemotaxis. In Leukocyte Chemotaxis: Methods, Physiology, and Clinical Implications. J. I. Gallin and P. G. Quie, editors. Raven Press, New York. 123-140.

6. Boxer, L. A., M. Yoder, S. Bonsib, M. Schmidt, P. Ho, R. Jersild, and R. L. Baehner. 1979. Effects of a chemotactic factor, $N$-formylmethionyl peptide, on adherence, superoxide anion generation, phagocytosis and microtubule assembly of human polymorphonuclear leukocytes. $J$. Lab. Clin. Med. 93: 506-514.

7. Becker, E. L., H. J. Showell, P. M. Henson, and L. S. Hsu. 1974. The ability of chemotactic factors to induce lysosomal enzyme release. I. The characteristics of release, the importance of surfaces, and the relation of enzyme release to chemotactic responsiveness. $J$. Immunol. 112: 2047-2054.

8. Smith, C. W., J. C. Hollers, R. A. Patrick, and C. Hassett. 1979. Motility and adhesiveness in human neutrophils, effects of chemotactic factors. J. Clin. Invest. 63: 221229.

9. Simchowitz, L., and I. Spilberg. 1979. Generation of superoxide radicals by human peripheral neutrophils activated by chemotactic factor. Evidence for the role of calcium. J. Lab. Clin. Med. 93: 583-593.

10. Gallin, J. I., D. G. Wright, and E. Schiffmann. 1978. Role of secretory events in modulating human neutrophil chemotaxis. J. Clin. Invest. 62: 1364-1374.

11. Van Epps, D. E., and R. C. Williams, Jr. 1976. Suppression of leukocyte chemotaxis by human IgA myeloma components. J. Exp. Med. 144: 1227-1242.

12. Van Epps, D. E., and L. L. Paxton. 1975. Chemotaxis as a preparative technique for human polymorphonuclear leukocytes. J. Lab. Clin. Med. 86: 309-314.

13. Zigmond, S. H., and J. G. Hirsch. 1973. Leukocyte loco- motion and chemotaxis: new methods for evaluation and demonstration of cell-derived chemotactic factor. $J$. Exp. Med. 137: 387-410.

14. Van Epps, D. E., J. S. Goodwin, and S. Murphy. 1978. Age-dependent variations in polymorphonuclear leukocyte chemiluminescence. Infect. Immun. 22: 57-61.

15. Harvath, L., and B. R. Andersen. 1979. Defective initiation of oxidative metabolism in polymorphonuclear leukocytes. N. Engl. J. Med. 300: 1130-1135.

16. Johnston, R. B., Jr., C. A. Godzik, and Z. A. Cohn. 1978. Increased superoxide anion production by immunologically activated and chemically elicited macrophages. $J$. Exp. Med. 148: 115-127.

17. Van Epps, D. E., K. Reed, and R. C. Williams, Jr. 1978. Suppression of human PMN bactericidal activity by human IgA paraproteins. Cell. Immunol. 36: 363-376.

18. Winfield, J. B., P. I. Lobo, and M. E. Hamilton. 1977. Fc receptor heterogeneity: immunofluorescent studies of $B$, $\mathrm{T}$, and "third population" lymphocytes in human blood with rabbit IgG b4/anti b4 complexes. J. Immunol. 119: 1778-1784.

19. Allen, R. C., S. J. Yevich, R. A. Orth, and R. W. Steele. 1974. The superoxide anion and single molecular oxygen: their role in the microbicidal activity of the polymorphonuclear leukocyte. Biochem. Biophys. Res. Commun. 60: 909-917.

20. Klebanoff, S. J. 1975. Antimicrobial systems of the polymorphonuclear leukocyte. In The Phagocytic Cell in Host Resistance. J. A. Bellanti and D. H. Dayton, editors. Raven Press, New York. 45-59.

21. Showell, H. J., R. J. Freer, S. H. Zigmond, E. Schiffmann, S. Aswanikumar, C. Corcoran, and E. L. Becker. 1976. The structure activity relations of synthetic peptides as chemotactic factors and inducers of lysosomal enzyme secretion for neutrophils. J. Exp. Med. 143: 1154-1169.

22. Klempner, M. S., and J. I. Gallin. 1978. Separation and functional characterization of human neutrophil subpopulations. Blood. 51: 659-669.

23. Iverson, D., L. DeChatetet, J. Spitznagel, and P. Wang. 1977. Comparison of NADH and NADPH oxidase activities in granules isolated from human polymorphonuclear leukocytes with a fluorometric assay. J. Clin. Invest. 59: 282-290.

24. Schleupner, C. J., and L. A. Glasgow. 1978. Peritoneal macrophage activation indicated by enhanced chemiluminescence. Infect. Immun. 21: 886-895.

25. Cross, A. S., and G. H. Lowell. 1978. Stimulation of polymorphonuclear leukocyte bactericidal activity by supernatants of activated human mononuclear cells. Infect. Immun. 22: 502-507.

26. Altman, L. C. 1978. Chemotactic lymphokines: a review. In Leukocyte Chemotaxis: Methods, Physiology, and Clinical Implications. J. I. Gallin and P. G. Quie, editors. Raven Press, New York. 267-286.

27. Issekutz, A. C., K. Lee, and W. D. Biggar. 1979. Enhancement of human neutrophil bactericidal activity by chemotactic factors. Infect. Immun. 24: 295-301. 